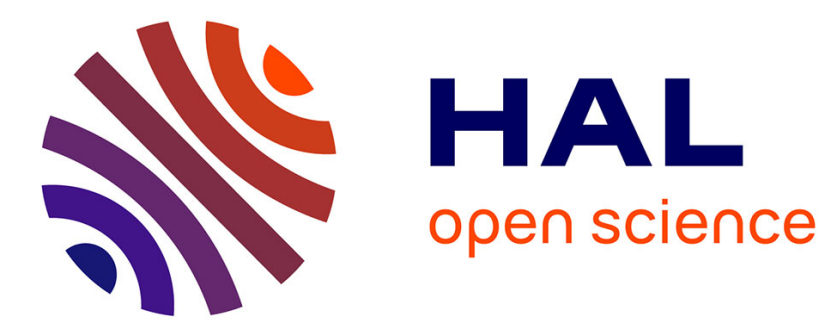

\title{
Sex pheromone in the moth Heliothis virescens is produced as a mixture of two pools: de novo and via precursor storage in glycerolipids
}

Stephen Foster, Karin Anderson, Jérome Casas

\section{- To cite this version:}

Stephen Foster, Karin Anderson, Jérome Casas. Sex pheromone in the moth Heliothis virescens is produced as a mixture of two pools: de novo and via precursor storage in glycerolipids. Insect Biochemistry and Molecular Biology, 2017, 87, pp.26-34. 10.1016/j.ibmb.2017.06.004 . hal-02573190

\author{
HAL Id: hal-02573190 \\ https://hal.science/hal-02573190
}

Submitted on 14 May 2020

HAL is a multi-disciplinary open access archive for the deposit and dissemination of scientific research documents, whether they are published or not. The documents may come from teaching and research institutions in France or abroad, or from public or private research centers.
L'archive ouverte pluridisciplinaire $\mathbf{H A L}$, est destinée au dépôt et à la diffusion de documents scientifiques de niveau recherche, publiés ou non, émanant des établissements d'enseignement et de recherche français ou étrangers, des laboratoires publics ou privés. 
Address correspondence to: Dr. Stephen Foster North Dakota State University Entomology Department NDSU Dept 7650

PO Box 6050 Fargo, ND 58108-6050 U.S.A Ph. 1-701-231-6444 Fax 1-701-231-8557 Email: stephen.foster@ndsu.edu

Sex pheromone in the moth Heliothis virescens is produced as a mixture of two pools: de novo and via precursor storage in glycerolipids

Stephen P. Foster ${ }^{1}$, Karin G. Anderson ${ }^{1}$ and Jérôme Casas ${ }^{2}$

${ }^{1}$ Entomology Department, North Dakota State University, PO Box 6050, Fargo, North Dakota 58108-6050, U.S.A and ${ }^{2}$ Université de Tours, Institut de Recherche sur la Biologie de l'Insecte, UMR CNRS 7261, 37200 Tours, FRANCE 
Abstract

40 Most species of moths use a female-produced volatile sex pheromone, typically produced

41 via de novo fatty acid synthesis in a specialized gland, for communication among mates.

42 While de novo biosynthesis of pheromone (DNP) is rapid, suggesting transient precursor

43 acids, substantial amounts of pheromone precursor (and other) acids are stored,

44 predominantly in triacylglycerols in the pheromone gland. Whether these stored acids are

45 converted to pheromone later or not has been the subject of some debate. Using a

46 tracer/tracee approach, in which we fed female Heliothis virescens $\mathrm{U}-{ }^{13} \mathrm{C}$-glucose, we

47 were able to distinguish two pools of pheromone, in which precursors were temporally

48 separated (after and before feeding on labeled glucose): DNP synthesized from a mixed

49 tracer/tracee acetyl CoA pool after feeding, and pheromone made from precursor acids

50 primarily synthesized before feeding, which we call recycled precursor fat pheromone

51 (RPP). DNP titer varied from high (during scotophase) to low (photophase) and with

52 presence/absence of pheromone biosynthesis activating neuropeptide (PBAN), in accord

53 with native pheromone titer previously observed. By contrast, RPP was constant

54 throughout the photoperiod and did not change with PBAN presence/absence. The

55 amount of RPP (6.3-10.3 ng/female) was typically much lower than that of DNP,

56 especially during the scotophase (peak DNP, $105 \mathrm{ng} /$ female). We propose an integral role

57 for stored fats in pheromone biosynthesis, in which they are hydrolyzed and re-esterified

58 throughout the photoperiod, with a small proportion of liberated precursor acyl CoAs

59 being converted to pheromone. During the sexually active period, release of PBAN

60 results in increased flux of glucose (from trehalose) and hydrolyzed acids entering the 
61 mitochondria, producing acetyl CoA precursor for de novo fat and pheromone

62 biosynthesis.

63

64

65 Keywords: Chemical communication; stable isotope; tracer/tracee; mass isotopomer

66 distribution analysis; Noctuidae; Lepidoptera.

67

68 


\section{Introduction}

70 The use of volatile sex pheromones to bring mates together for copulation is prevalent

71 among the group of insects known as moths (order: Lepidoptera) (Allison and Cardé,

72 2016). Female moths produce and/or release a sex pheromone, typically a blend of

73 closely related chemicals, from a specialized gland usually located on the intersegmental

74 membrane between the $8^{\text {th }}$ and $9^{\text {th }}$ abdominal segments (Ma and Ramaswamy, 2003).

75 Elevated production and release of pheromone typically occur during a defined temporal

76 period of the day, when a species is sexually active (Groot, 2014). In many species of

77 moths, the period of elevated production is governed by the release of the pheromone

78 biosynthesis-activating neuropeptide (PBAN) from the corpora cardiaca into the

79 hemolymph (Blomquist et al., 2011; Rafaeli and Jurenka, 2003).

81 Species of moths that biosynthesize so-called "Type 1" sex pheromone components do so

82 by a route involving rapid de novo fatty acid synthesis from acetyl CoA, followed by

83 desaturation and/or cytosolic $\beta$-oxidation of the alkyl chain and modification of the

84 carboxyl group to an alcohol, aldehyde or acetate ester (Ando et al., 2004; Blomquist et

85 al., 2011; Foster, 2016). De novo biosynthesis of pheromone requires a supply of acetyl

86 CoA precursor, which is provided by glycolysis/pyruvate oxidation of hemolymph

87 trehalose, and mitochondrial $\beta$-oxidation of fatty acids from glandular glycerolipids

88 (Foster and Anderson, 2015). In addition to providing fatty acids for $\beta$-oxidation,

89 glandular glycerolipids also contain relatively substantial amounts of pheromone

90 precursor acids, which may or may not subsequently be converted to pheromone (Bjostad

91 et al., 1987; Fang et al., 1995; Foster, 2005b; Matsumoto, 2010). For instance, in the 
92 silkworm moth, Bombyx mori, which uses a single component (bombykol) as its sex

93 pheromone, triacylglycerol stores of pheromone precursor acids accumulate throughout

94 the non-sexually active period. These are then hydrolyzed and reduced to pheromone

95 following release of PBAN during the sexually active period (Matsumoto, 2010). By

96 contrast, species such as the redbanded leafroller, Argyrotaenia velutinana, and the

97 European corn borer, Ostrinia nubilalis, which use highly specific ratios of geometric

98 isomers as pheromone components, may have a preponderance of the precursor acid of

99 the minor pheromone component over that of the major component stored in

100 glycerolipids (Bjostad et al., 1981; Foster, 2004). This suggests that there is little release

101 and conversion of these acids directly to pheromone. In these cases, fatty acids may still

102 be hydrolyzed from glycerolipids by lipases for $\beta$-oxidation, but the much greater

103 abundances of other acids will likely result in a relatively low release of pheromone

104 precursor acids with an insignificant effect on the ratio of pheromone components

105 produced.

106

107 Sex pheromone biosynthesis and glandular glycerolipids have been extensively studied in

108 the moth Heliothis virescens (Fabricius) (family: Noctuidae) (Choi et al., 2005; Foster

109 and Anderson, 2011; Foster, 2005a, b; Foster and Anderson, 2012; Groot et al., 2016;

110 Hagström et al., 2013), which uses a blend of (Z)-11-hexadecenal (Z11-16:Ald) and (Z)-

111 9-tetradecenal as its sex pheromone (Roelofs et al., 1974). Recently, using the stable

112 isotope tracer-tracee method of mass isotopomer distribution analysis (MIDA; Hellerstein

113 and Neese, 1999), we established that females use a roughly 2:1 ratio of carbohydrate

114 (from hemolymph trehalose) to stored fats as nutrients for production of acetyl CoA 
115 during de novo pheromone biosynthesis (Foster and Anderson, 2015). However, we

116 noticed that a significant portion of the unlabeled pheromone could not have been

117 produced from the tracer/tracee pool of acetyl CoA used for de novo-produced

118 pheromone (DNP). We concluded that this unlabeled pheromone must arise from a

119 distinct precursor pool, containing no labeled acetyl CoA, most likely from pheromone

120 precursor acids, specifically (Z)-11-hexadecenoate (Z11-16:Acyl), hexadecanoate

121 (16:Acyl), and octadecanoate (18:Acyl), synthesized and stored before introduction of the

122 tracer. These stored acids may be converted directly, without mitochondrial $\beta$-oxidation,

123 to pheromone (Choi et al., 2005).

124

125 This result suggested that recycling of stored precursor fats converted directly to

126 pheromone ("recycled precursor fat pheromone"; RPP) might be an important contributor

127 to pheromone production in H. virescens, particularly at different times of the

128 photoperiod or with increased age. For example, most of the pheromone produced early

129 in the scotophase, and released first by females, could be produced via this route before

130 DNP production contributed more. Since we are developing a quantitative model to

131 describe pheromone production and release in $H$. virescens, we sought to (i) characterize

132 the overall production pathway structure, (ii) estimate some of its parameters, in

133 particular the relative contributions of DNP and RPP, (iii) determine whether their

134 contributions were time dependent with respect to photoperiod and age, and (iv)

135 determine whether PBAN influenced the production of RPP and DNP, as it does for

136 native pheromone (Eltahlawy et al., 2007; Groot et al., 2005).

137 


\section{2. Methods and Materials}

$140 \quad$ 2.1. Insects

141 Heliothis virescens were from a colony maintained at NDSU, Fargo, but originating from

142 a colony previously established at USDA-ARS BRL, Fargo, and recently supplemented

143 with insects supplied by Dr. F.A. Gould (North Carolina State University, Raleigh, NC).

144 Larvae were reared at $25^{\circ} \mathrm{C}$ under a 16:8 L:D photoperiod and fed on a wheatgerm-casein

145 diet until they pupated, after which they were sexed and the two sexes maintained

146 separately under the same environmental conditions as larvae.

148 Adults were collected daily and categorized as 1-d-old the day after eclosion, 2-d-old,

149 two days after eclosion, etc. Prior to the start of an experiment, adults were starved and

150 denied access to any liquids. The stable isotope tracer was introduced by allowing an

151 adult to feed on $25 \mu \mathrm{l}$ of a $10 \%(\mathrm{w} / \mathrm{v})$ aqueous solution of $\mathrm{U}-{ }^{13} \mathrm{C}$-glucose $(99 \%$;

152 Cambridge Isotope Laboratories, Cambridge, MA) as a drop on a watch glass; only

153 females that consumed the full amount were used in experiments. The labeled glucose,

154 absorbed rapidly into hemolymph trehalose, undergoes glycolysis and oxidation to

155 generate ${ }^{13} \mathrm{C}_{1,2}$-acetyl-CoA tracer, which is incorporated into pheromone and gland fats

156 (Foster and Anderson, 2011; Foster and Anderson, 2012).

\subsection{Extraction, Derivatization and Chemical Analysis}

159 The pheromone gland of a female was extruded by applying gentle force to the abdomen 160 and then excised with fine forceps. For pheromone extraction, the gland was placed in 5 
$161 \mu \mathrm{l}$ of $n$-heptane containing $25 \mathrm{ng}$ of (Z)-11-tetradecenal (Z11-14:Ald) as an internal

162 standard and allowed to extract for at least $1 \mathrm{~h}$ at ambient temperature before analysis.

163 For fatty acid extraction, the gland was placed in $50 \mu \mathrm{l}$ of a 2:1 mixture of $\mathrm{CH}_{2} \mathrm{Cl}_{2}$ :

$164 \mathrm{MeOH}$ along with $250 \mathrm{ng}$ of tripentadecanoin (Sigma-Aldrich, St Louis, MO) as an

165 internal standard, and allowed to extract at $-15^{\circ} \mathrm{C}$ overnight.

167 The pheromone extract was injected into an Agilent 7890/5978A gas

168 chromatograph/mass spectrometer (GC/MS), whereas the fat extract was subjected to

169 base methanolysis to generate fatty acid methyl esters (FAMEs). Briefly, after extraction,

170 the solvent was decanted and removed by a gentle stream of nitrogen. Then, $50 \mu \mathrm{l}$ of 0.5

$171 \mathrm{M}$ methanolic $\mathrm{KOH}$ was added and allowed to react for $1 \mathrm{~h}$ at ambient temperature before

$17250 \mu 1$ of $1 \mathrm{M} \mathrm{HCl}(\mathrm{aq})$ was added along with $25 \mu \mathrm{l}$ of heptane. The solution was subjected

173 to rapid vortexing for $30 \mathrm{sec}$., before the heptane layer (top) was decanted and injected in

174 the GC/MS for analysis.

175

176 The GC used helium at a constant flow of $1.5 \mathrm{ml} \cdot \mathrm{min}^{-1}$ as carrier gas, and splitless

177 injection. The column was a $30 \mathrm{~m}$ x $0.25 \mathrm{~mm}$ i.d $\times 250 \mu \mathrm{m}$ film thickness ZBWax

178 (Phenomenex, Torrance, CA) and the oven temperature was programmed from $80^{\circ} \mathrm{C}$

179 (delay of $1 \mathrm{~min}$ ) to 180 at $15^{\circ} \mathrm{C} \cdot \mathrm{min}^{-1}$, then to 190 at $5^{\circ} \mathrm{C} \cdot \mathrm{min}^{-1}$, and finally to 220 at

$18020^{\circ} \mathrm{C} \cdot \mathrm{min}^{-1}$. The MS was operated with electron impact ionization at $70 \mathrm{eV}$ and used in

181 the single ion monitoring mode. The MS source and quadrupole were set at $230^{\circ} \mathrm{C}$ and

$182150^{\circ} \mathrm{C}$, respectively. 
184 For the pheromone analyses, the following $\mathrm{m} / \mathrm{z}$ were monitored: 192 for the internal

185 standard (Z11-14:Ald), 220, 222, and 224, for Z11-16:Ald (we only analyzed the major

186 pheromone component, as it comprises $>90 \%$ of the mass of the pheromone and is

187 biosynthesized similarly to the minor component Z9-14:Ald; Choi et al., 2005; Teal et al.,

188 1986). The $m / z 192$ and 220 were monitored because they are ions $\left[\left(\mathrm{M}-\mathrm{H}_{2} \mathrm{O}\right)^{+}\right]$of intact

189 (unlabeled) carbon skeletons of Z11-14:Ald and Z11-16:Ald, respectively, and carry

190 more ion current than their respective parent ions. The $m / z 222$ and 224 are the $\mathrm{M}+1$

191 (+one ${ }^{13} \mathrm{C}_{2}$ unit) and $\mathrm{M}+2$ (+two ${ }^{13} \mathrm{C}_{2}$ unit) isotopomers of Z11-16:Ald.

192

193 The FAMEs of Z11-16:Acyl and 16:Acyl were analyzed similarly by monitoring their

194 molecular ions, namely m/z 268 (M+0 for Z11-16:Acyl), 270, (M+1 for Z11-16:Acyl,

$195 \mathrm{M}+0$ for 16:Acyl), 272 (M+2 for Z11-16:Acyl, M+1 for 16:Acyl) and 274 (M+2 for

196 16:Acyl), along with $\mathrm{m} / z 256$ of the internal standard methyl pentadecanoate.

\section{2.3. Mass Isotopomer Distribution Analysis}

199 MIDA is a combinatorial approach to determine isotopic (precursor) enrichment in a

200 monomeric pool used to synthesize a polymer, following the introduction of a stable

201 isotope-labeled monomer (Hellerstein and Neese, 1992; Wolfe and Chinkes, 2005). It

202 accomplishes this by measuring intensities of both unlabeled and labeled isotopomers of

203 the polymer, while accounting for abundances of natural isotopes. The precursor

204 enrichment, i.e., the proportion of labeled monomeric units in the resulting polymer, can

205 be calculated using the pattern of isotopomers. An advantage of MIDA is that it is not

206 subject to isotopic discrimination in the precursor pool (Hellerstein and Neese, 1999). 
208 We used MIDA to calculate precursor enrichment following introduction of the tracer

$209 \quad\left({ }^{13} \mathrm{C}_{2}\right.$-acetyl $\left.\mathrm{CoA}\right)$ formed after insects had fed on $\mathrm{U}-{ }^{13} \mathrm{C}$-glucose. We analyzed females

210 at least $16 \mathrm{~h}$ after they had fed, so that the precursor pool and pheromone or pheromone

211 precursor acids were in isotopic equilibrium (Foster and Anderson, 2011; Foster and

212 Anderson, 2012). To calculate precursor enrichment, tracer/tracee ratios (TTRs) of singly

$213(\mathrm{M}+1)$ and doubly $(\mathrm{M}+2)$ labeled (i.e., with one and two ${ }^{13} \mathrm{C}_{2}$ units, respectively)

214 isotopomers were calculated for the acetyl CoA octomers Z11-16:Ald, Z11-16:Acyl and

215 16:Acyl as follows:

216 (1) $\mathrm{TTR}(\mathrm{M}+1)=(\mathrm{M}+1 / \mathrm{M}+0)_{\text {post }}-(\mathrm{M}+1 / \mathrm{M}+0)_{\text {pre }}$

217 (2) $\operatorname{TTR}(\mathrm{M}+2)=(\mathrm{M}+2 / \mathrm{M}+0)_{\text {post }}-(\mathrm{M}+2 / \mathrm{M}+0)_{\text {pre }}-\mathrm{dT}_{1} \times \mathrm{TTR}(\mathrm{M}+1)$

218 Where 'pre' and 'post' subscripts, respectively, refer to the intensities of isotopomers

219 before and after tracer is introduced. We used theoretically calculated values of the pre

220 intensities (using known natural isotopic abundances), rather than experimentally

221 determined ones, as previously (Foster and Anderson, 2011; Foster and Anderson, 2012)

222 we found little difference between the two. The term $\mathrm{dT}_{1}$ is the contribution of the $\mathrm{M}+1$

223 isotopomer spectrum to the $\mathrm{M}+2$ isotopomer. Then, precursor enrichment (" $p$ ", in molar

224 percent excess) of an octomer can be calculated by:

225 (3) $p=2 \times[\operatorname{TTR}(\mathrm{M}+2) / \mathrm{TTR}(\mathrm{M}+1)] \div[7+\mathrm{TTR}(\mathrm{M}+2) / \mathrm{TTR}(\mathrm{M}+1)]$

227 In order to calculate the amount of unlabeled pheromone not produced by de novo

228 biosynthesis (i.e., RPP) after addition of the tracer, we used precursor enrichment to

229 predict the entire isotopomer pattern (for all 9 isotopomers, $M+0-8$ ). Then, by using the 
230 observed intensity of the $\mathrm{M}+2$ isotopomer (minus any natural isotopic contributions from

231 the $\mathrm{M}+0$ and $\mathrm{M}+1$ isotopomers), we calculated the expected intensity of the $\mathrm{M}+0$

232 isotopomer produced via de novo synthesis from the labeled/unlabeled acetyl CoA pool.

233 This was subtracted from the intensity of the observed $\mathrm{M}+0$ isotopomer to allow the

234 amount (relative to the internal standard) of RPP to be determined. Similarly, using the

235 sum of all (nine) isotopomers expected for a given $p$, we calculated the amount of DNP.

236 De novo-produced (i.e., labeled, including expected $\mathrm{M}+0$ isotopomer, after $\mathrm{U}-{ }^{13} \mathrm{C}$ -

237 glucose was ingested) and previously synthesized (unlabeled, before feeding) stored Z11-

238 16:Acyl and 16:Acyl were calculated similarly.

\section{2.4. Isotopic fractionation}

241 To test whether quantification of both DNP and RPP pools was affected by significant

242 isotopic fractionation from use of the ${ }^{13} \mathrm{C}$-tracer, we fed $1 \mathrm{~d}$ females either unlabeled

243 ( $>99 \%$ pure and natural isotopic composition; Sigma-Aldrich, St Louis, MO) or ${ }^{13} \mathrm{C}-$

244 labeled glucose at the end of the scotophase. The following day, at the beginning of the

245 scotophase (i.e., $16 \mathrm{~h}$ later), we quantified the amount of unlabeled pheromone in females

246 fed unlabeled glucose, and the amounts of DNP and RPP in females fed labeled glucose.

247 The total amounts (i.e., DNP + RPP for females fed U- ${ }^{13} \mathrm{C}$-glucose vs total pheromone in

248 females fed unlabeled glucose) for each treatment were compared.

250 2.5. Effect of age and time of photoperiod

251 We determined the amount of DNP and RPP in females of different ages and at different

252 times during the scotophase, in order to test whether the respective amounts in the gland 
253 varied through time. For this, we fed females of different ages $(0,1,2$, and $3 \mathrm{~d}) \mathrm{U}-{ }^{13} \mathrm{C}-$

254 glucose at the end of the scotophase and left them for at least $18 \mathrm{~h}$ before analyzing

255 pheromone at hour 2 of the scotophase (hereafter, hours of the photoperiod are referred to

256 as S2, P16, etc., with the letter indicating scotophase or photophase and the number the

257 hour of the respective period). Females fed at $1 \mathrm{~d}$ were analyzed more extensively,

258 starting at P14 of the subsequent photophase and then every $2 \mathrm{~h}$ throughout the

259 subsequent scotophase (i.e., when $2 \mathrm{~d}$ old). In addition, $1 \mathrm{~d}$ females were fed $6 \mathrm{~h}$ into their

260 first complete photophase (i.e., the photophase preceding the scotophase in which they

261 were analyzed every $2 \mathrm{~h}$ ) and analyzed $24 \mathrm{~h}$ later (at P6). From 5-13 females were

262 analyzed for each time point.

263

264 2.6. Effect of decapitation

265 To test whether the amounts of DNP and RPP are influenced by the absence of PBAN,

266 we fed $1 \mathrm{~d}$ females $\mathrm{U}-{ }^{13} \mathrm{C}$-glucose at the end of the scotophase and decapitated them $18 \mathrm{~h}$

267 later (at Scot2). Decapitation stops PBAN reaching the pheromone gland and

268 consequently results in a rapid decrease in pheromone titer (Rafaeli and Jurenka, 2003).

269 We sampled females at 0 (immediately prior to decapitation), 0.25. 0.5, 1.0, 1.5, 2, 4, 6

270 and $24 \mathrm{~h}$ later. Five to eight females were analyzed at each time.

272 In the second part, $1 \mathrm{~d}$ females were fed $\mathrm{U}^{13} \mathrm{C}$-glucose and then, in the following

273 scotophase (i.e., at least $16 \mathrm{~h}$ later) analyzed for total labeled (i.e., carbon chain

274 synthesized after introduction of the labeled glucose) and excess unlabeled (i.e., carbon

275 chain synthesized before introduction of the labeled glucose or from a pool of precursor 
276 that was not derived from labeled glucose) FAMEs of Z11-16:Acyl and 16:Acyl. Three

277 groups of females were analyzed: (i) intact females at S0, (ii) intact females at S6, and

278 (iii) females decapitated at S0 and analyzed at S6.

\subsection{Effect of PBAN}

281 We conducted the complementary experiment to the previous one by injecting PBAN

282 into decapitated females and determining the effect on DNP and RPP. One-day-old

283 females were fed at the end of the scotophase and, immediately upon ingestion of the U-

$284{ }^{13} \mathrm{C}$-glucose, decapitated. The decapitated females were then left for $18 \mathrm{~h}$, at which time

285 they were either injected with 5 pmole of PBAN (HeZ; Bachem, Torrance, CA) in saline

$286(2.5 \mu \mathrm{l})$ or the same volume of saline $\left(\mathrm{NaCl}, 187.5 \mathrm{mmol} . \mathrm{l}^{-1}, \mathrm{KCl}, 4.83 \mathrm{mmol.1} \mathrm{l}^{-1}, \mathrm{CaCl}_{2}\right.$,

$2872.61 \mathrm{mmol} . \mathrm{l}^{-1}$, Hepes, $10 \mathrm{mmol. \textrm {l } ^ { - 1 }}, \mathrm{pH}=6.8$ ). They were analyzed for DNP and RPP at 0

288 (only saline injected), 0.25, 0.5, 1.0, 1.5 and $4.0 \mathrm{~h}$ later.

290 A similar experimental approach was adopted for analysis of total labeled and excess

291 unlabeled FAMEs of Z11-16:Acyl and 16:Acyl, except females were analyzed at 0 (no

292 PBAN or saline injected), 0.5 and $4.0 \mathrm{~h}$ (for both saline- and PBAN-injected females).

\section{2.8. Statistical analyses}

295 For the effect of photoperiod and age, we used ANCOVA with RPP, DNP or precursor

296 enrichment as dependent variables, age as a covariate and time of photoperiod as a

297 categorical independent variable, after first checking normality and heteroscedasity of the

298 data. For all other data, we used ANOVA to test for differences, again after checking the 
normality and heteroscedasity of the data, and tested differences among means by post-

300 hoc Tukey-Kramer HSD tests with $\alpha$ set at $\mathrm{P}=0.05$. In the decapitation experiment, we

301 made two temporal comparisons: the first was of RPP and DNP titers over the first $6 \mathrm{~h}$ of

302 decapitation, and the second was a binary comparison for both RPP and DNP titers just

303 prior to and $24 \mathrm{~h}$ after, decapitation.

304

305 3. Results

306

307 3.1. Isotopic fractionation effect

308 At the start of the scotophase, females fed unlabeled glucose the previous day had a mean

309 pheromone titer of $17.9 \pm 2.7 \mathrm{ng} /$ female $(\mathrm{N}=10)$, whereas females fed $\mathrm{U}-{ }^{13} \mathrm{C}$-glucose had a

310 mean total RPP+DNP titer of $22.2 \pm 3.5 \mathrm{ng} /$ female $(\mathrm{N}=14)$; these means were not different

311 (ANOVA, $\mathrm{F}_{1,22}=0.86, \mathrm{p}=0.36$ ). Thus, any isotopic effects that occurred in the

312 biosynthesis of pheromone from $\mathrm{U}^{13} \mathrm{C}$-glucose did not affect pheromone gland titer.

313

\section{3.2. Effect of photoperiod and age}

315 At all times of the photoperiod and all ages tested, females had substantial and reasonably

316 constant titers of RPP in the gland, varying from a mean of $6.3 \pm 1.7$ to $10.3 \pm 1.4 \mathrm{ng} / \mathrm{female}$

317 (Fig. 1a). ANCOVA, with amount of RPP as the dependent variable, showed no effect of

318 time of photoperiod $\left(\mathrm{F}_{5,65}=0.64, \mathrm{p}=0.67\right)$, but an effect of age $\left(\mathrm{F}_{1,65}=5.59, \mathrm{p}=0.021\right)$.

319 Essentially, the amount of RPP declined slightly with increasing age of female, but the

320 amount of RPP produced throughout the photoperiod did not differ. 
322 The amount of DNP was generally much greater than that of RPP, especially during the

323 scotophase (Fig. 1a). It also showed much greater change over time (both with

324 photoperiod and age), varying from a mean of $9.6 \pm 1.9$ to $105.2 \pm 25.0 \mathrm{ng} /$ female. This

325 difference was most noticeable between titers in the photophase and (especially middle of

326 the) scotophase, in accord with previous studies on native pheromone titer in $H$. virescens

327 and many other species of moths (e.g., Foster, 2005b; Groot, 2014; Heath et al., 1991;

328 McNeil, 1991). ANCOVA, with amount of DNP as the dependent variable, revealed

329 highly significant effects for both time of photoperiod $\left(\mathrm{F}_{5,65}=5.96, \mathrm{p}<0.001\right)$ and age

$330\left(\mathrm{~F}_{1,65}=27.4, \mathrm{p}<0.001\right)$. There was a strong correlation $\left(\mathrm{F}_{1,70}=40.2, \mathrm{P}<0.001 ; \mathrm{R}^{2}=0.36\right)$

331 between RPP and $\log \mathrm{DNP}$ (Fig. 1b).

332

333 ANCOVA with precursor enrichment (Fig. 1c) as the dependent variable showed no

334 effect of photoperiod $\left(\mathrm{F}_{5,65}=1.89, \mathrm{p}=0.11\right)$, but an effect of age $\left(\mathrm{F}_{1,65}=10.2, \mathrm{p}=0.002\right)$,

335 consistent with decreasing levels of native hemolymph trehalose in older females (Foster

336 et al., 2014).

\section{3.3. Effect of decapitation}

340 In the first $6 \mathrm{~h}$ after decapitation, DNP and RPP exhibited different patterns (Fig. 2a).

341 DNP showed a rapid and significant decrease (ANOVA, F $F_{7,31}=4.87, \mathrm{p}<0.001$ ) from ca.

34220 to $1.5 \mathrm{ng} /$ female, consistent with the known effect of decapitation on total pheromone

343 titer in decapitated females (Eltahlawy et al., 2007). The mean amounts of DNP 4 and $6 \mathrm{~h}$

344 after decapitation were lower (Tukey-Kramer HSD test) than the amounts prior to, or 
$3450.25 \mathrm{~h}$ after, decapitation. By contrast, the mean amount of RPP did not change over the

346 first $6 \mathrm{~h}$ of decapitation (ANOVA, $\left.\mathrm{F}_{7,31}=0.73, \mathrm{p}=0.65\right)$, ranging from 5.3-8.8

$347 \mathrm{ng} /$ female. Twenty four hours after decapitation, both DNP and RPP titers had declined

348 to very low levels, both lower (ANOVA, $\mathrm{F}_{1,11}=11.4, \mathrm{P}=0.006$ and $\mathrm{F}_{1,11}=12.3, \mathrm{P}=$

3490.005 , respectively) than their respective values before decapitation.

351 Precursor enrichment did not change over the first $6 \mathrm{~h}$ following decapitation (ANOVA,

$352 \mathrm{~F}_{7,31}=0.75, \mathrm{P}=0.63$; Fig. 2b). However, after $24 \mathrm{~h}$ of decapitation, precursor enrichment

353 was slightly greater $\left(\mathrm{F}_{1,11}=10.6, \mathrm{P}=0.008\right)$ than that prior to decapitation (Fig. $\left.2 \mathrm{~b}\right)$.

355 With regard to fatty acyl stores, females decapitated for $6 \mathrm{~h}$ had a lower titer (ANOVA, $356 \mathrm{~F}_{2,19}=7.32, \mathrm{P}=0.004$; Tukey-Kramer HSD test) of labeled Z11-16:Acyl than did intact

357 females at the start of the scotophase or intact females $6 \mathrm{~h}$ into the scotophase (Fig. 2c).

358 Titers of unlabeled Z11-16:Acyl in females decapitated $6 \mathrm{~h}$ were similar to those in intact

359 females $6 \mathrm{~h}$ into the scotophase, but less than those in females at the start of the

360 scotophase (ANOVA F $F_{2,19}=6.15, \mathrm{P}=0.004$; Tukey-Kramer HSD test; Fig. 2c). Of note

361 is that $6 \mathrm{~h}$ of decapitation over this period yielded similar ratios of labeled to unlabeled

362 Z11-16:Acyl as at the start of the scotophase (in intact females), whereas leaving females

363 intact over this period (i.e., through the scotophase) resulted in a relative decline in the

364 amount of unlabeled Z11-16:Acyl (compared to labeled Z11-16:Acyl) over the $6 \mathrm{~h}$ of the 365 scotophase. 
367 For both labeled (ANOVA, $\mathrm{F}_{2,19}=0.56, \mathrm{P}=0.58$ ) and unlabeled 16:Acyl (ANOVA, $\mathrm{F}_{2,19}$

$368=0.56, \mathrm{P}=0.58$ ), there were no differences in titer among any of the treatments (Fig. $2 \mathrm{~d}$ ).

369 In contrast to the similar amounts of unlabeled and labeled Z11-16:Acyl, the amount of

370 unlabeled 16:Acyl was much greater than that of labeled 16:Acyl, indicating a relatively

371 slow turnover of this very large pool.

372

373 3.4. Effect of PBAN

374 Injection of PBAN into females decapitated $16 \mathrm{~h}$ earlier led to a rapid increase (ANOVA,

$\left.375 \mathrm{~F}_{5,42}=8.38, \mathrm{P}<0.001\right)$ in DNP (Fig. 3a), such that $1 \mathrm{~h}$ after injection the amount of DNP

376 was greater (Tukey-Kramer HSD test) than that prior to injection (i.e., at $t=0$ ). DNP

377 increased throughout the $4 \mathrm{~h}$ of the experiment, although the amount $4.0 \mathrm{~h}$ after PBAN

378 injection was not different to that $1.5 \mathrm{~h}$ after injection (Tukey-Kramer HSD test).

379 Injection of PBAN also resulted in an initial small increase (ANOVA, $\mathrm{F}_{5,42}=3.36, \mathrm{P}=$

380 0.012) in RPP (Fig. 3a), with the amount $1 \mathrm{~h}$ after injection being greater (Tukey-Kramer

381 HSD test) than that prior to injection. After that, the level of RPP plateaued. The amount

382 of RPP was always much less than that of DNP in females injected with PBAN.

383 Precursor enrichment (Fig. 3b) showed a small change over the experiment (ANOVA,

$384 \mathrm{~F}_{5,42}=2.45, \mathrm{P}=0.049$ ), with enrichment $4 \mathrm{~h}$ after injection of PBAN being greater than

385 that $0.25 \mathrm{~h}$ after injection (Tukey-Kramer HSD test).

387 Injection of PBAN stimulated a large increase (ANOVA, $\mathrm{F}_{4,39}=337.7, \mathrm{P}<0.001$ ) in

388 labeled Z11-16:Acyl (Fig. 3c); $4 \mathrm{~h}$ after injection, females had more (Tukey-Kramer HSD

389 test) labeled Z11-16:Acyl than did females of all other treatments (which were similar). 
390 The amount of unlabeled Z11-16:Acyl increased slightly with PBAN injection (ANOVA,

$391 \mathrm{~F}_{4,39}=3.41, \mathrm{P}=0.018$ ), with the amount $4 \mathrm{~h}$ after PBAN injection being greater (Tukey-

392 Kramer HSD test) than that prior to injection (i.e., at $t=0)$. Neither labeled $\left(F_{4,39}=2.24\right.$,

$393 \mathrm{P}=0.083)$ nor unlabeled $\left(\mathrm{F}_{4,39}=1.77, \mathrm{P}=0.15\right) 16$ :Acyl titers changed with PBAN

394 injection (Fig. 3d).

395

396 4. Discussion

398 4.1. Identification of two pathways

399 Through feeding ${ }^{13} \mathrm{C}$-labeled glucose to female $H$. virescens, we demonstrated that

400 females produce two pools of pheromone: DNP, which incorporates ${ }^{13} \mathrm{C}$-tracer, and RPP,

401 which does not. At most times, especially during the scotophase, the titer of DNP was

402 much larger than that of RPP and, importantly, their respective titer profiles differed with

403 regard to photoperiod and presence/absence of PBAN. The photoperiodic pattern of

404 DNP titer closely resembled that of native titer in H. virescens (Foster, 2005b; Heath et

405 al., 1991) and other moths (Groot, 2014; McNeil, 1991), with a substantial difference

406 between the sexually inactive (photophase, titer low) and active (scotophase, titer high)

407 periods. By contrast, RPP titer was constant throughout the photoperiod. For DNP (and

408 native pheromone) this photoperiodic variation is explained by the presence/absence of

409 PBAN acting on the gland (Eltahlawy et al., 2007; Groot et al., 2005; Rafaeli and

410 Jurenka, 2003). RPP titer was largely independent of the presence/absence of PBAN,

411 although females decapitated for ca. 16-24 h showed a small decline in RPP, which could

412 be rectified by injection of PBAN. This, together with the concomitant changes in 
413 precursor enrichment, showing a small decline in fat usage for DNP, suggest that

414 extended absence of PBAN, or perhaps another effect of decapitation, may result in other

415 (than fat and pheromone synthesis) minor effects on fat metabolism in the gland. The

416 small effect of age on both DNP and RPP is consistent with a senescent decline in

417 biosynthetic capability in the gland (Foster, 2005b; Raina et al., 1986)

419 The incorporation of ${ }^{13} \mathrm{C}$-label into DNP and its lack of incorporation into RPP, show the 420 two pools of pheromone must be biosynthesized by distinct, but related, routes (Fig. 4).

421 In our experiments, Z11-16:Ald DNP was biosynthesized de novo, after females fed on

422 labeled glucose. This route involves a cytosolic pool of labeled/unlabeled acetyl CoA,

423 formed from glycolysis/pyruvate oxidation and $\beta$-oxidation of stored fatty acids (Foster

424 and Anderson, 2015), and synthesis of transient 16:Acyl and Z11-16:Acyl precursors

425 (Fig. 4) (Choi et al., 2005). Since label from glucose is incorporated into pheromone very

426 rapidly after feeding (Foster and Anderson, 2011), the lack of label in RPP, at least $16 \mathrm{~h}$

427 after feeding, shows that it cannot be produced from the same cytosolic acetyl CoA pool.

428 Instead, it must be derived largely from precursors in the female before adult feeding

429 (i.e., from nutrients acquired during larval feeding).

431 As suggested previously (Foster and Anderson, 2015), the most likely candidates for a

432 precursor of RPP are glandular glycerolipid stores of the pheromone precursor(s), Z11-

433 16:Acyl, 16:Acyl, and perhaps 18:Acyl. These acids are stored predominantly in

434 triacylglycerols in the gland, mostly on $s n-1$ and $s n-3$ positions of the glycerol backbone

435 (Foster, 2005b). Following hydrolysis by glandular lipases, these precursor acids can be 
436 converted directly to pheromone (Choi et al., 2005; see also Fig. 4). Therefore, assuming

437 pheromone gland lipases (Du et al., 2012) are typical triacylglycerol lipases, with little

438 selectivity toward acyl groups of similar chain length (Watt and Steinberg, 2008), then

439 the most probable precursor for production of RPP in our experiments, by virtue of its

440 much greater abundance (Foster, 2005b; see also, Figs. 2b, 3b), is unlabeled 16:Acyl,

441 although unlabeled 18:Acyl may also contribute. Stored Z11-16:Acyl probably

442 contributes little to RPP measured in our experiments, since its isotopic enrichment was

443 similar to that of pheromone (see also Foster et al., 2014). Hence, hydrolysis of stores of

444 this moiety and conversion to pheromone, while strictly speaking also forming "recycled

445 precursor fat" pheromone, will yield apparent increases in DNP from the isotopomer

446 patterns. The much larger amount of stored 16:Acyl relative to Z11-16:Acyl, combined

447 with the small production of RPP from 16:Acyl, suggests that only a small amount of

448 DNP measured in our experiments was produced from stored Z11-16:Acyl. This may

449 account for the small amount of "apparent" DNP observed throughout the photophase in

450 our experiments, although it is possible that this is produced by a low level of de novo

451 production in the absence of PBAN.

\section{4.2. PBAN control}

454 The small amount of RPP compared to the large amount of 16:Acyl (and to a lesser 455 extent, Z11-16:Acyl) available in the gland of female $H$. virescens suggests limited but 456 constant lipolysis that is largely independent of PBAN, in contrast to the situation in $B$. 457 mori (Du et al., 2012; Matsumoto, 2010). However, during PBAN stimulation in $H$.

458 virescens, acyl CoAs are also used for $\beta$-oxidation, producing acetyl CoA precursor for 
459 DNP (Foster and Anderson, 2015), and perhaps for energy for cell function. Since fats

460 are used to produce up to one third of precursor for DNP (Foster and Anderson, 2015), it

461 is likely that there is considerably more lipolysis than indicated by RPP production alone.

462 When PBAN is absent, the likely fate of most acyl CoAs is re-esterification but when

463 present, most or a significant portion of liberated acyl CoAs is $\beta$-oxidized. During PBAN

464 stimulation, acyl CoAs may be compartmentalized, with de novo-synthesized acyl CoAs

465 (16:Acyl) being primarily converted directly to pheromone, while hydrolyzed, stored acyl

466 CoAs are $\beta$-oxidized, producing precursor for de novo synthesis. We do not suggest that

467 PBAN directly controls the flux of fatty acids into the mitochondria. Rather, it likely

468 controls this flux indirectly, as well as glycolytic flux, by controlling a downstream

469 process, such as conversion of acetyl CoA to malonyl CoA by acetyl CoA carboxylase

470 (Eltahlawy et al., 2007; Rafaeli and Jurenka, 2003)

472 Compartmentalization of different sources of acyl CoAs with different metabolic fates is 473 well established. In mice, the enzymes glycerol-3-phosphate acyltransferase (GPAT) and 474 carnitine palmitoyl transferase (CPT) compete for acyl CoAs at the outer mitochondrial

475 membrane, with GPAT preferentially loading de novo-synthesized acyl CoAs for

476 incorporation into glycerolipids, while CPT preferentially loads acyl CoAs from

477 glycerolipids for carnitine esterification and transport across the mitochondrial membrane 478 for $\beta$-oxidation (Cooper et al., 2015). This compartmentalization of newly synthesized

479 and stored fats is supported by our FAME experiments. Six hours after decapitation, both 480 labeled and unlabeled Z11-16:Acyl stores had declined by similar amounts; females 481 continue to use stores but cannot replenish them since they are not synthesizing new fatty 
482 acids. By contrast, only unlabeled Z11-16:Acyl stores declined in intact females over the

483 same period; both labeled and unlabeled stores were utilized as in decapitated females,

484 but labeled stores were replenished via the tracer/tracee pool. In females injected with

485 PBAN, there was an expected increase in labeled Z11-16:Acyl stores, but also a small

486 increase in unlabeled stores, but only to levels similar to those prior to decapitation.

488 These trends were not apparent in 16:Acyl stores, perhaps because the amounts are much

489 greater and less subject to apparent change, and also because our dissections of glands

490 almost certainly contained other tissue in which 16:Acyl was abundant, masking any

491 effects peculiar to the gland.

492

493 4.3. Contribution of stored fat to pheromonal communication

494 The fact that a small amount of RPP is constantly produced throughout the entire

495 photoperiod, regardless of whether DNP is being synthesized or not, suggests that its

496 production is largely a consequence of constant hydrolysis of fats from glycerolipids, for

497 either $\beta$-oxidation or re-esterification, with only a small portion of free precursor acyl

498 CoAs (predominantly 16:Acyl) reaching the endoplasmic reticulum for conversion to

499 pheromone (Hagström et al., 2013). Furthermore, the amount of pheromone produced

500 directly (RPP route) by female H. virescens from stored precursor fats is relatively small,

501 especially in comparison to the amount of DNP produced during the sexually active

502 period. Therefore, RPP is likely, at best, to make a small contribution to the pheromone

503 released, especially for younger females attracting males for their first mating. 504 
505 This dual pathway of pheromone production has been established, so far, only for $H$.

506 virescens. Hence, we do not know whether or not RPP contributes more or less to

507 pheromone production and release in other species of moths. Its contribution likely

508 depends on the amounts of pheromone precursor acids stored, as well as glandular

509 lipolytic activity. In the case of B. mori, females appear to produce all their pheromone

510 from precursor acyl CoAs hydrolyzed from triacylglycerols. However, photoperiodic

511 control of pheromone biosynthesis is somewhat unusual in this species, in that release of

512 PBAN appears to control fatty acid reduction (Matsumoto, 2010), rather than fatty acid

513 synthesis, as found for $H$. virescens (Eltahlawy et al., 2007) and other moths studied

514 (Rafaeli and Jurenka, 2003). Thus, fats are synthesized and stored in the absence of

515 PBAN, but not mobilized and reduced to pheromone until PBAN is released (Matsumoto,

516 2010). By contrast, in $H$. virescens, new precursor acyl CoAs are synthesized only when

517 DNP is also being produced, with only a small portion being stored in triacylglycerols;

518 their primary fate being pheromone (Foster and Anderson, 2012). It is also worth noting

519 that $H$. virescens adults feed (on nectar) and hence can replenish carbohydrate used

520 throughout the adult life; more than two thirds of acetyl CoA precursor for DNP

521 production in $H$. virescens is derived from hemolymph carbohydrate (trehalose) (Foster

522 and Anderson, 2015). Many species of moths, including B. mori, do not feed as adults

523 and hence may be more dependent upon stored fats for pheromone production, as both

524 DNP and RPP. Studying nutrient use for pheromone production across a range of species,

525 with different life history traits, is needed to determine whether recycling of stored

526 precursor fats is more than a minor route for contributing to pheromone production in

527 moths. 
529 Acknowledgments

530 This work was funded in part by USDA Hatch Project ND02388. The purchase of the

531 GC/MS system was funded in part by a USDA-NIFA Instrument Grant (2015-07238). 532 


\section{REFERENCES CITED}

535

536

537

538

539

540

541

542

543

544

545

546

547

548

549

550

551

552

553

554

555

556

557

558

559

560

561

562

563

564

565

566

567

568

569

570

571

572

573

574

575

576

Allison, J.D., Cardé, R.T., 2016. Pheromone communication in moths: evolution, behavior and application. University of California Press, Oakland, California, p. 401.

Ando, T., Inomata, S., Yamamoto, M., 2004. Lepidopteran sex pheromones., in: Schulz, S. (Ed.), The Chemistry of Pheromones and Other Semiochemicals I. Springer Berlin / Heidelberg, pp. 51-96.

Bjostad, L.B., Wolf, W.A., Roelofs, W.L., 1981. Total lipid analysis of the sex pheromone gland of the redbanded leafroller moth, Argyrotaenia velutinana, with reference to pheromone biosynthesis. Insect Biochem. 11, 73-79.

Bjostad, L.B., Wolf, W.A., Roelofs, W.L., 1987. Pheromone biosynthesis in lepidopterans: desaturation and chain shortening., in: Prestwich, G.D., Blomquist, G.J. (Eds.), Pheromone Biochemistry. Academic Press, New York, pp. 77-120.

Blomquist, G.J., Jurenka, R., Schal, C., Tittiger, C., 2011. Pheromone production: biochemistry and molecular biology, in: Gilbert, L.I. (Ed.), Insect Endocrinology. Academic Press, San Diego, CA, pp. 523-567.

Choi, M.Y., Groot, A., Jurenka, R.A., 2005. Pheromone biosynthetic pathways in the moths Heliothis subflexa and Heliothis virescens. Arch Insect Biochem Physiol 59, 5358.

Du, M., Yin, X., Zhang, S., Zhu, B., Song, Q., An, S., 2012. Identification of Lipases Involved in PBAN Stimulated Pheromone Production in Bombyx mori Using the DGE and RNAi Approaches. PLoS ONE 7, e31045.

Eltahlawy, H., Buckner, J.S., Foster, S.P., 2007. Evidence for two-step regulation of pheromone biosynthesis by the pheromone biosynthesis-activating neuropeptide in the moth Heliothis virescens. Arch Insect Biochem Physiol 64, 120-130.

Fang, N., Teal, P.E.A., Tumlinson, J.H., 1995. PBAN regulation of pheromone biosynthesis in female tobacco hornworm moths, Manduca sexta (L.). Arch Insect Biochem Physiol 29, 35-44.

Foster, S., Anderson, K., 2011. The use of mass isotopomer distribution analysis to quantify synthetic rates of sex pheromone in the moth Heliothis virescens. J Chem Ecol 37, 1208-1210.

Foster, S.P., 2004. Fatty acid and sex pheromone changes and the role of glandular lipids in the Z-Strain of the European corn borer, Ostrinia nubilalis (Hübner). Arch Insect Biochem Physiol 56, 73-83. 
Foster, S.P., 2005a. The fate of topically applied fatty acids in the sex pheromone gland of the moth Heliothis virescens. Insect Biochemistry and Molecular Biology 35, 10211031.

Foster, S.P., 2005b. Lipid analysis of the sex pheromone gland of the moth Heliothis virescens. Arch Insect Biochem Physiol 59, 80-90.

Foster, S.P., 2016. Toward a quantitative paradigm for sex pheromone production in moths., in: Allison, J.D., Cardé, R.T. (Eds.), Pheromone communication in moths: evolution, behavior and application. University of California Press, Oakland,, CA, pp. 113-126.

Foster, S.P., Anderson, K.G., 2012. Synthetic rates of key stored fatty acids in the biosynthesis of sex pheromone in the moth Heliothis virescens. Insect Biochemistry and Molecular Biology 42, 865-872.

Foster, S.P., Anderson, K.G., 2015. Sex pheromones in mate assessment: analysis of nutrient cost of sex pheromone production by females of the moth Heliothis virescens. The Journal of Experimental Biology 218, 1252-1258.

Foster, S.P., Anderson, K.G., Harmon, J.P., 2014. Increased allocation of adult-acquired carbohydrate to egg production results in its decreased allocation to sex pheromone production in mated females of the moth Heliothis virescens. The Journal of Experimental Biology 217, 499-506.

Groot, A.T., 2014. Circadian rhythms of sexual activities in moths: a review. Frontiers in Ecology and Evolution 2.

Groot, A.T., Dekker, T., Heckel, D.G., 2016. The Genetic Basis of Pheromone Evolution in Moths. Ann Rev Entomol 61, 99-117.

Groot, A.T., Fan, Y., Brownie, C., Jurenka, R.A., Gould, F., Schal, C., 2005. Effect of PBAN on pheromone production by mated Heliothis virescens and Heliothis subflexa females. J Chem Ecol 31, 15-28.

620

Hagström, Å.K., Walther, A., Wendland, J., Löfstedt, C., 2013. Subcellular localization of the fatty acyl reductase involved in pheromone biosynthesis in the tobacco budworm, Heliothis virescens (Noctuidae: Lepidoptera). Insect Biochemistry and Molecular Biology 43, 510-521.

Heath, R.R., McLaughlin, J.R., Proshold, F., Teal, P.E.A., 1991. Periodicity of female sex pheromone titer and release in Heliothis subflexa and $H$. virescens (Lepidoptera: Noctuidae). Ann. Entomol. Soc. Am. 84, 182-189. 
Hellerstein, M.K., Neese, R.A., 1992. Mass isotopomer distribution analysis: a technique 622 for measuring biosynthesis and turnover of polymers. American Journal of Physiology -

Hellerstein, M.K., Neese, R.A., 1999. Mass isotopomer distribution analysis at eight years: theoretical, analytic, and experimental considerations. American Journal of Physiology - Endocrinology And Metabolism 276, E1146-1170.

Ma, P.W.K., Ramaswamy, S.B., 2003. Biology and ultrastructure of sex pheromoneproducing tissue., in: Blomquist, G.J., Vogt, R.C. (Eds.), Insect pheromone biochemsitry and molecular biology. Elsevier Academic Press., London, pp. 19-51.

Matsumoto, S., 2010. Molecular mechanisms underlying sex pheromone production in moths. Bioscience, Biotechnology, and Biochemistry 74, 223-231.

McNeil, J.N., 1991. Behavioral ecology of pheromone-mediated communication in moths and its importance in the use of pheromone traps. Ann Rev Entomol 36, 407-430.

Rafaeli, A., Jurenka, R., 2003. PBAN regulation of pheromone biosynthesis in female moths, in: Blomquist, G.J., Vogt, R.C. (Eds.), Insect Pheromone Biochemistry and Molecular Biology. Elsevier, Amsterdam, pp. 107-136.

Raina, A.K., Klun, J.A., Stadelbacher, E.A., 1986. Diel periodicity and effect of age and mating on female sex pheromone titer in Heliothis zea (Lepidoptera: Noctuidae). Ann. Entomol. Soc. Am. 79, 128-131.

Roelofs, W.L., Hill, A.S., Cardé, R.T., Baker, T.C., 1974. Two sex pheromone components of the tobacco budworm moth, Heliothis virescens. Life Sci 14, 1555-1562.

Teal, P.E.A., Tumlinson, J.H., Heath, R.R., 1986. Chemical and behavioral analyses of volatile sex pheromone components released by calling Heliothis virescens (F.) females (Lepidoptera: Noctuidae). J Chem Ecol 12, 107-126.

Watt, Matthew J., Steinberg, Gregory R., 2008. Regulation and function of triacylglycerol lipases in cellular metabolism. Biochemical Journal 414, 313-325.

Wolfe, R.R., Chinkes, D.L., 2005. Isotope Tracers in Metabolic Research, Second Edition. John Wiley \& Sons, Inc. 


\section{Captions}

662 Figure 1. Mean titers ( \pm SEM) of de novo-produced pheromone (DNP) and recycled 663 precursor fat pheromone (RPP) in female Heliothis virescens of different age and 664 times of the photoperiod. a) DNP and RPP. (b) Relation between DNP (log scale) and 665 RPP titers. (c) Pheromone precursor enrichment (in molar percent excess; MPE) of DNP. 666 Age of female (in days) given below figures. Numbers above bars are numbers of 667 replicates.

669 Figure 2. Mean titers $( \pm$ SEM) of various pheromone-related moieties in female 670 Heliothis virescens fed $\mathrm{U}^{13} \mathrm{C}$-glucose the previous day and decapitated at the start of 671 the subsequent scotophase. A) De novo-produced pheromone (DNP) and recycled 672 precursor fat pheromone (RPP). (b) Pheromone precursor enrichment (in molar percent 673 excess; MPE) of DNP. Labeled and unlabeled (c) (Z)-11-hexadecenoate (Z11-16:Acyl) 674 and (d) hexadecanoate (16:Acyl). Decap6 = decapitated (at S0) for 6 h. Different letters 675 (of the same case) above bars indicate means that are different $(\mathrm{P}<0.05$, Tukey-Kramer 676 test), while numbers in parentheses are the numbers of replicates.

678 Figure 3. a) Mean titers $( \pm$ SEM) of various pheromone-related moieties in 679 decapitated female Heliothis virescens fed $\mathrm{U}-{ }^{13} \mathrm{C}$-glucose and analyzed following 680 injection with pheromone biosynthesis-activating neuropeptide (PBAN). a) De novo681 produced pheromone (DNP) and recycled precursor fat pheromone (RPP). (b) Pheromone 682 precursor enrichment (in molar percent excess; mpe) for DNP. Labeled and unlabeled (c) 683 (Z)-11-hexadecenaoate (Z11-16:Acyl) and (d) hexadecanoate (16:Acyl). Letters above 
684 bars indicate means that are different $(\mathrm{P}<0.05$, Tukey-Kramer test), while numbers in

685 parentheses are numbers of replicates.

686

687 Figure 4. Biosynthesis of pheromone [(Z)-11-hexadecenal] in the gland of Heliothis

688 virescens females by two distinct routes: de novo-produced pheromone (DNP) and

689 recycled precursor fat pheromone (RPP). Processes that occur throughout the day have

690 grey arrows, while processes that occur primarily during the sexually active period

691 (scotophase) have black arrows. Features are: (1) stored acyl CoAs are continuously

692 hydrolyzed and re-esterified to glycerolipids, (2) DNP production is controlled by release

693 of pheromone biosynthesis activating neuropeptide (PBAN) from the corpora cardiaca,

694 which acts on a step in de novo synthesis of hexadecanoate (16:Acyl), and (3) this

695 indirectly controls fluxes of $\beta$-oxidation of glandular fats and glycolysis/pyruvate

696 oxidation of glucose (from hemolymph trehalose) to produce acetyl CoA precursor. Z11-

697 16:Acyl is the pheromone precursor acid (Z)-11-hexadecenoate.

698

699

700

701

702

703 
a)

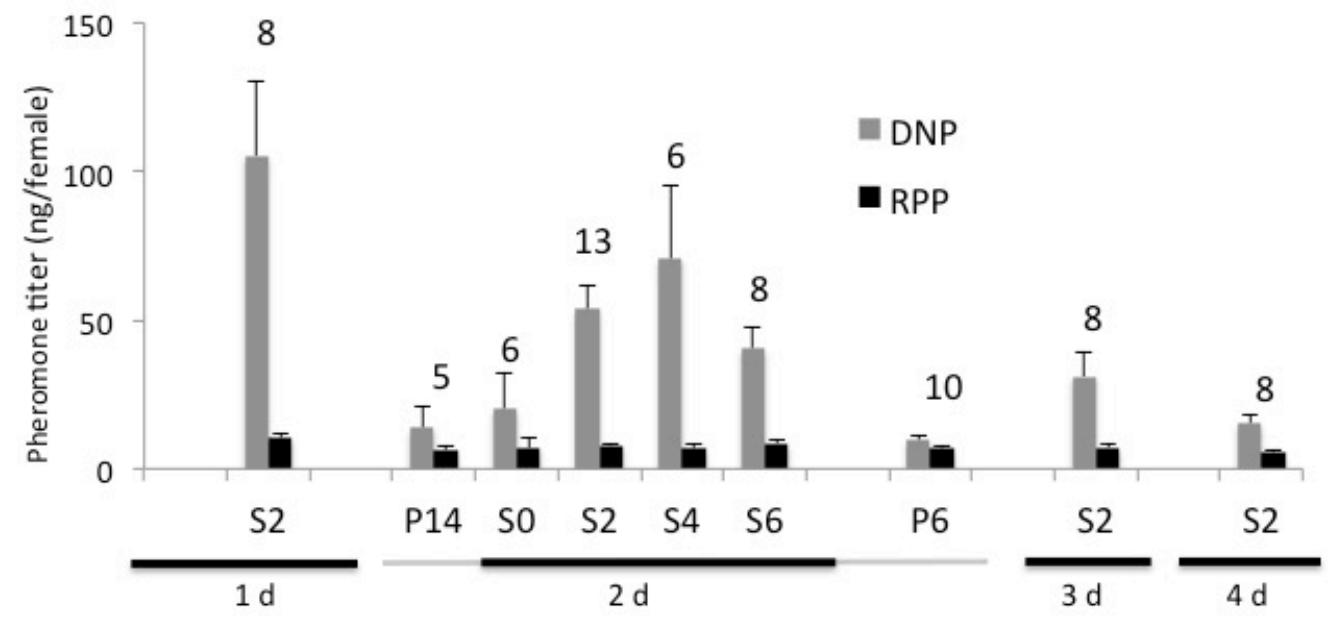

b)

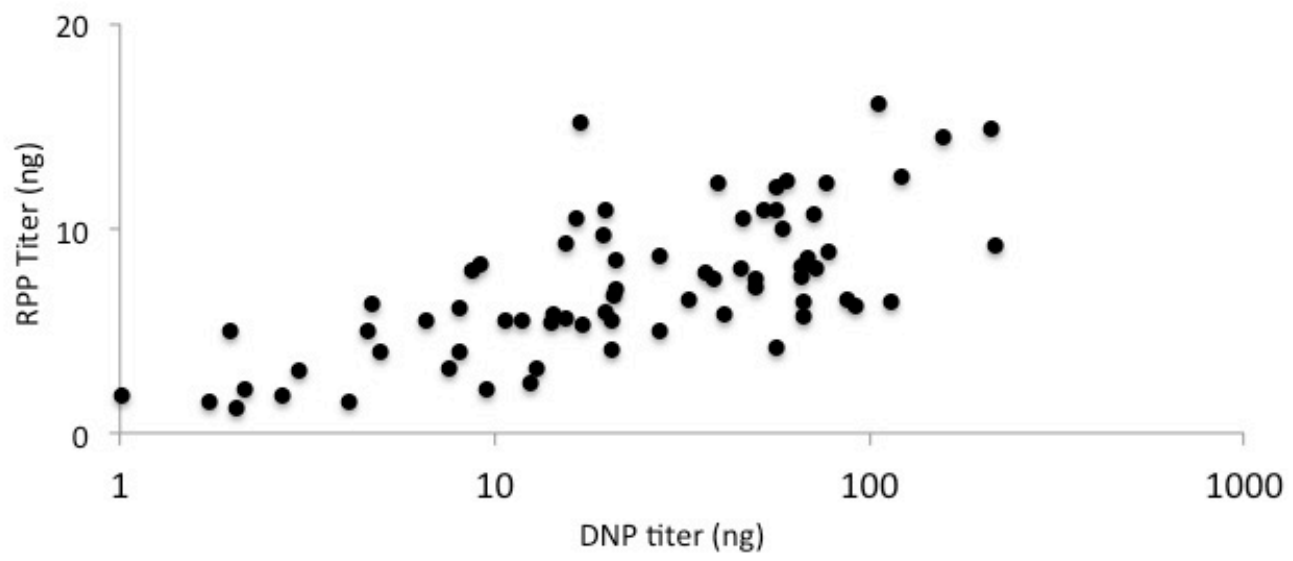

c)

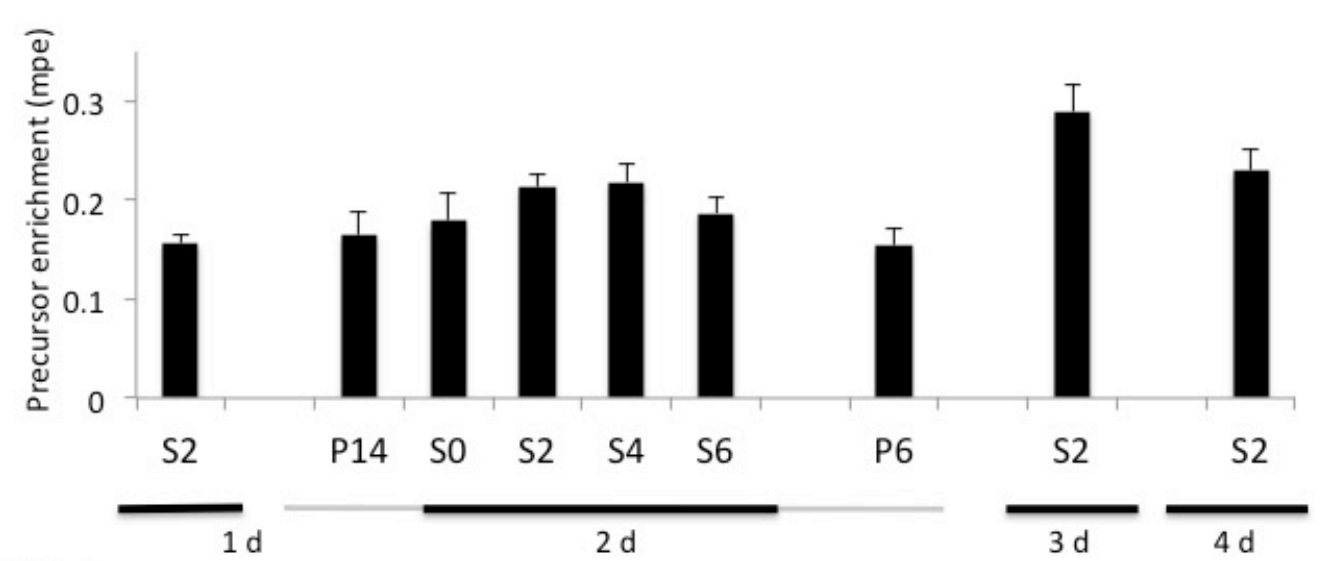

Figure 1

704

705

706 


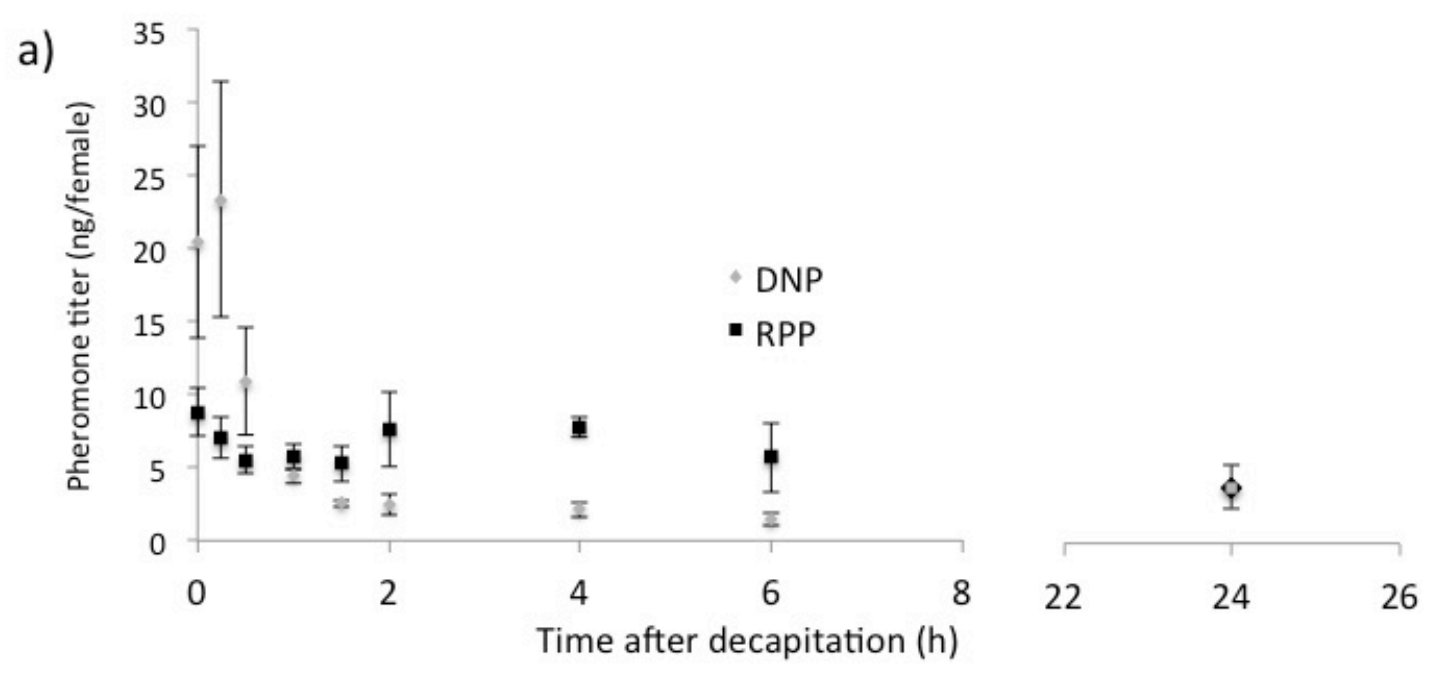

b)

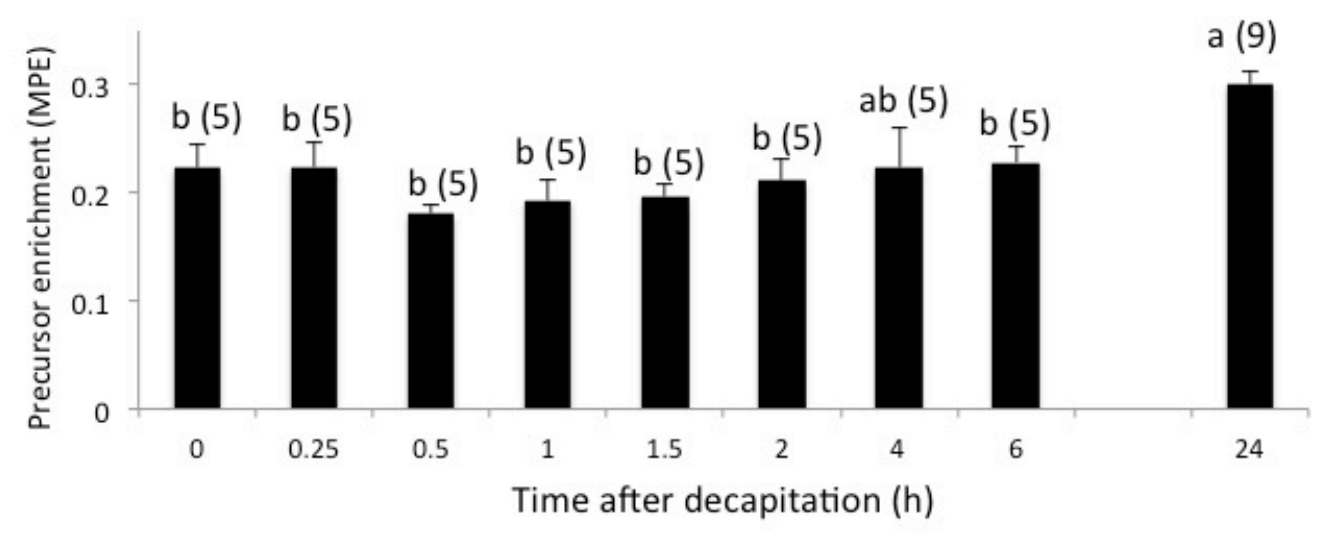

c)

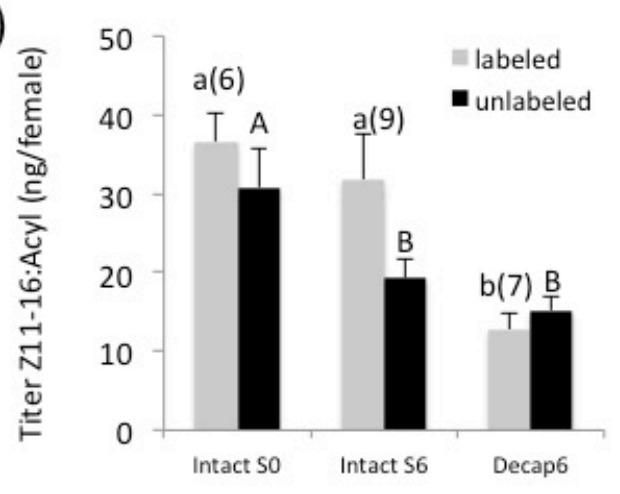

d)

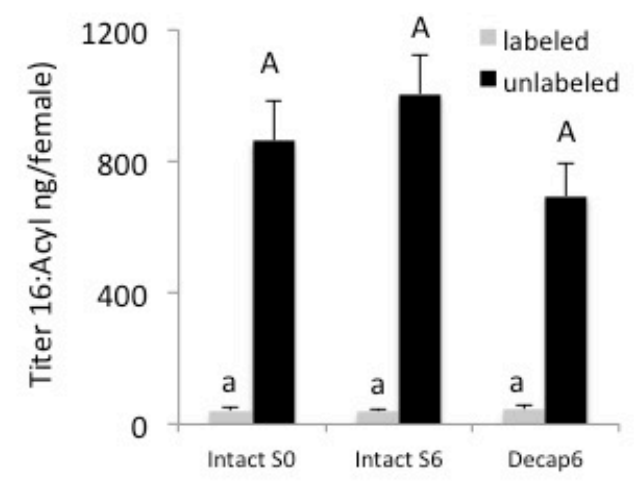

Figure 2 
a)

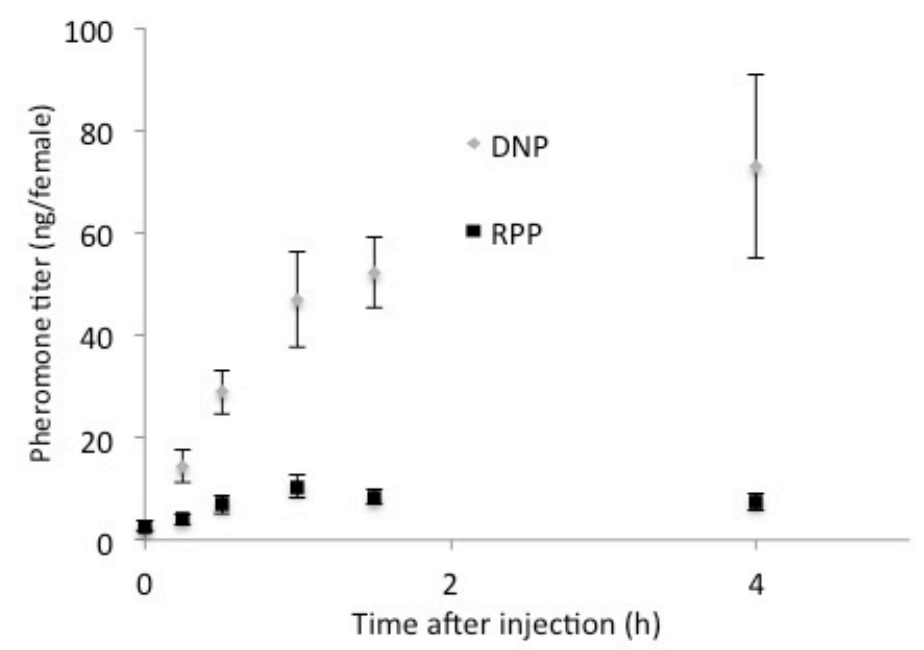

b)

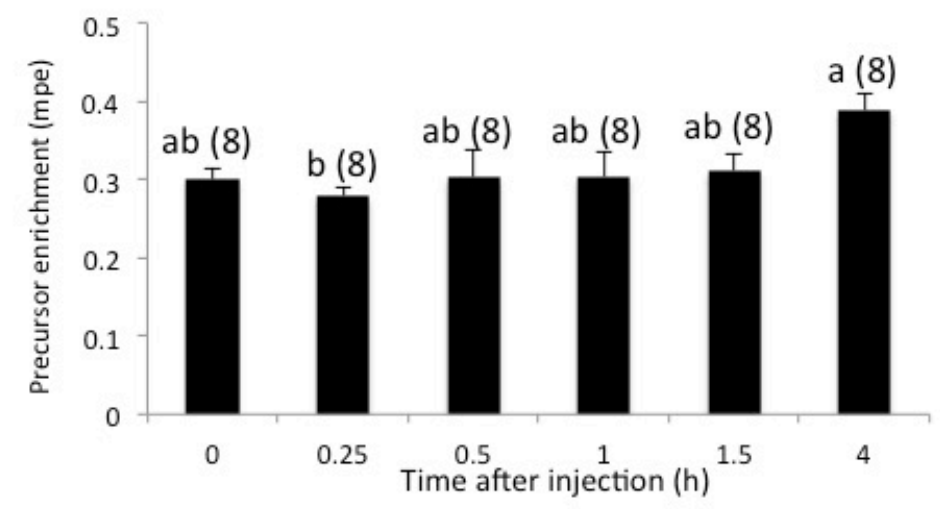

c)

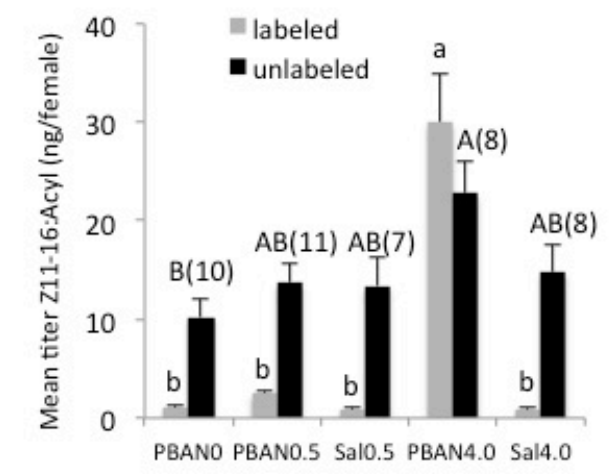

d)

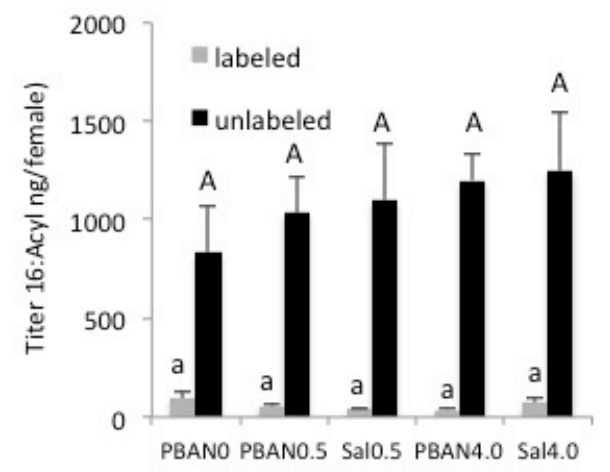

Figure 3 


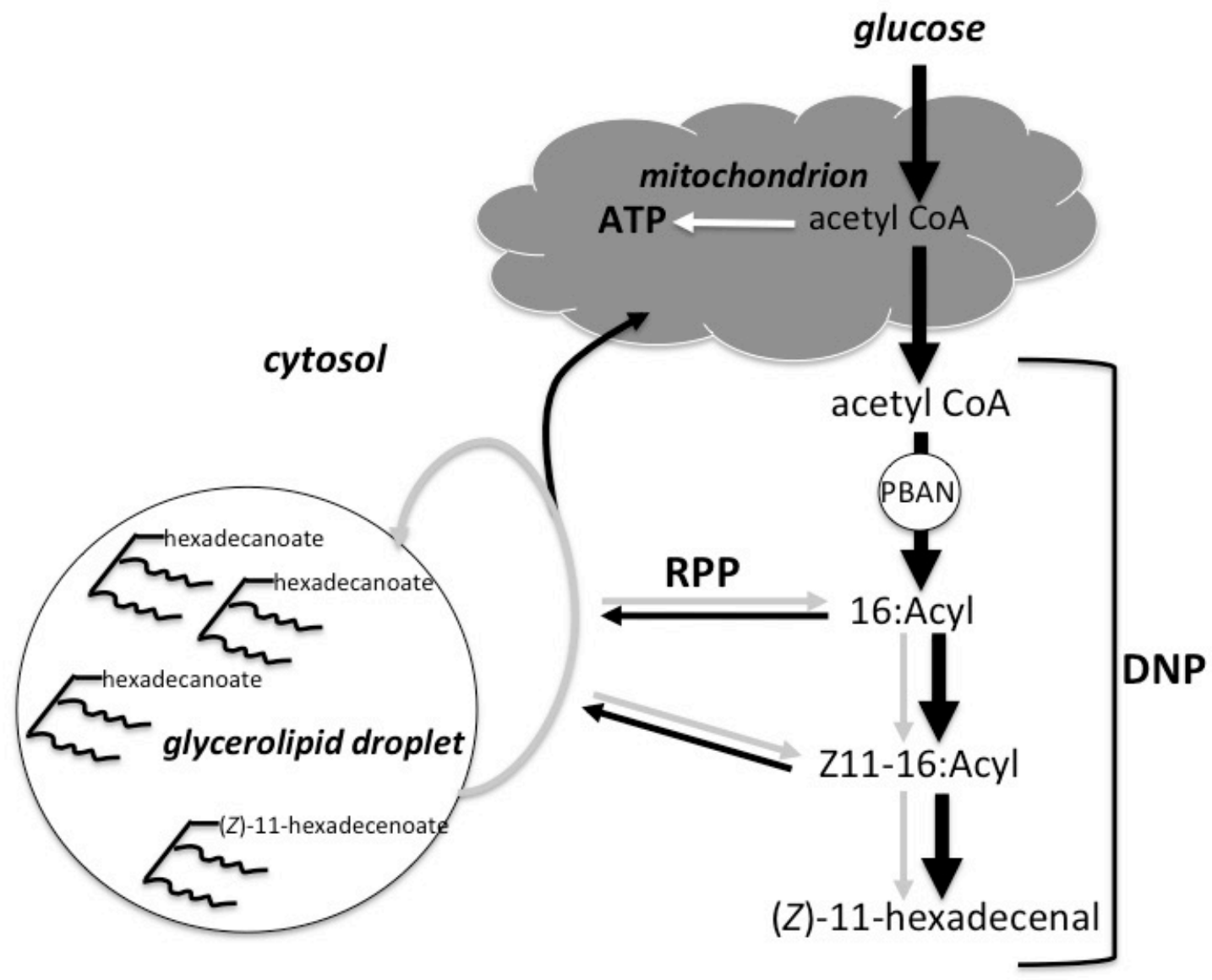

Figure 4 